\title{
Content is King? The Effectiveness of Message Content, Personalization, and Location in Mobile In-Store Advertising
}

\author{
Rabea Schrage \\ Chair of Marketing \\ Heinrich-Heine-University \\ Düsseldorf \\ rabea.schrage@hhu.de
}

\author{
Prof. Dr. Marco Hubert \\ Dep. of Management \\ Aarhus University \\ $\underline{\text { mah@mgmt.au.dk }}$
}

\author{
Dr. Marc Linzmajer \\ Institute of Retail Management \\ University of St. Gallen \\ marc.linzmajer@unisg.ch
}

\begin{abstract}
Smartphones have become a vital part of our lives, a personal assistant helping us as customers mastering everyday tasks. For example, the new stationary supermarket Amazon Go implements customers' smartphones as an integral part for completing the grocery shopping process (e.g. used to check-in, for payment). As in-store communication over smartphones becomes increasingly important, retailers pay their attention to mobile in-store advertising, which offers them new perspectives to interact with customers at the point of sale. In this study, we therefore investigate the effectiveness of mobile in-store advertising by empirically examining which combination of message content is most effective for different in-store locations. Drawing on Construal Level Theory, we conduct an online choice experiment, using a simulated supermarket shopping task. Results show that personalization in combination with price promotions are most effective regarding the choice of the target product when spatially close to the product. Moreover, personalization strengthens the impact of ad content at the shelf, representing an amplifying effect on product choice.
\end{abstract}

\section{Introduction}

Due to the rapid growth of mobile commerce and the wide adoption of mobile devices, retailers are recently increasing their attention to mobile in-store advertising, which offers new perspectives to interact with customers at the point of sale [1,2]. Mobile advertising is defined as "advertising messages delivered through mobile devices" (p. 68) [3]. With the advancements of new in-store technologies (e.g. iBeacons, RFID), retailers are now able to provide customers with location-based (tailored to the customers' geographic positions) (p. 2) [4] and personalized content (appropriate to the customers' personal needs) [5] within the store [6]. For example, customers can receive mobile advertising for a specific product referring to their individual purchase history when located next to the shelf [7].

Previous research acknowledges that the location at which the mobile advertisement pops up is crucial for its effectiveness. In particular, Molitor et al. [8] found that customers are more likely to redeem mobile coupons when they were spatially close to the retailer, while Spiekermann et al. [9] provided evidence that proximity of coupon delivery to the place of redemption has a significant effect on campaign success.

Furthermore, existing research highlights the importance of personalization for mobile advertising. $\mathrm{Xu}[10]$ identified personalization as the key factor influencing consumers' attitudes toward mobile advertising. Thongpapanl and Ashraf [11] found that personalized information increases purchase intention, and Linzmajer et al. [7] showed that personalized product recommendations delivered via smartphones increased the real amounts spent instore.

Regarding ad content, retailers have, on the one hand, the possibility to use monetary promotions, which are widely applied in order to attract consumers to the stationary store and to increase the store traffic [12]. Prior research confirmed the positive effects of price promotions on consumers' purchase behavior [13, 14]. On the other hand, retailers can use non-monetary promotions. Literature has recognized the importance of recommendations as a way to exploit valuable consumer information (e.g. [7]).

While previous research has focused on the single effects of location, personalization and content, recent research explores effects of different combinations of those strategies. For example, Luo et al. [15] explored the effectiveness of temporal and geographical targeting on consumer responses to mobile promotions. The authors found that temporal and geographical targeting individually increase the 
sales purchases, while the effect of employing these two strategies simultaneously is not straightforward, confirming a curvilinear relationship. In the specific context of stationary retailing, Bues et al. [16] investigated how mobile in-store advertising influences the customer's purchase intention in a retail setting. They found that location and personalization interact with each other. More precisely, personalized mobile in-store messages are less effective when the message is received close to the product than farther away. As this represents an interesting result in the context of mobile in-store advertising, however, the underlying mechanism explaining this effect remains unclear. Further research is therefore needed to understand how customers respond to mobile in-store promotions and how messages need to be designed in order to enhance effectiveness.

Against this background, the aim of the present study is to investigate the effectiveness of in-store mobile advertising in the context of stationary retailing by empirically examining the single effect of the mobile promotions' location, personalization and ad content as well as their interplay on customer's actual choice. The following research question is in the centre of scrutiny: Which combinations of mobile in-store advertising (location, personalization and ad content) have the strongest impact on customer's product choice?

In order to answer the research question, we draw on Construal Level Theory (CLT) proposed by Trope and Liberman [17], following the call for scholars to investigate CLT especially in the context of mobile technology [18]. We contribute to existing mobile instore advertising research as we are one of the first to conduct an online choice experiment using a simulated supermarket shopping task.

\section{Theoretical Background \& Hypotheses Development}

\subsection{Construal Level Theory}

CLT represents a framework for explaining how psychological distance affects individuals' behavior [19]. Any action can be mentally construed at different levels [20, 17]. According to CLT, mental construal can be defined as "a representation of something independent of direct experience" (p. 4) [21], [17] (e.g. past, future, other people, hypothetical events) and is formed on a continuum ranging from high-level construals to low-level construals [22]. Mental construals are considered to transcend the immediate situation and the psychologically distant object [17]. A major determinant of what level of construal is activated is the psychological distance of a specific event or object [23]. Psychological distance is defined as ,a subjective experience that something is close or far away from the self, here, and now" ( $\mathrm{p}$. 440) [17] and refers to one owns perception of how distant an object is from the self. Psychological distance can occur in four dimensions, namely: temporal, spatial, social and hypothetical distance. Psychological distance is therefore egocentric. Its reference point is the self in the here and now [17]. A central assumption of CLT is that with increasing psychological distance to an object, individuals construe more abstract representations (high-level construals). Conversely, as psychological distance for the same object decreases, individuals construe more concrete representations (low-level construals) [17].

Decisions of everyday life such as shopping decisions are typically connected to goals [18]. In the context of goal-oriented actions, CLT distinguishes between desirability and feasibility. Desirability refers to the means of an action's end state (the "why" aspect of the action), whereas feasibility pertains to the means for reaching that end-state (the "how" aspect of the action) [24, 17]. As a result, CLT predicts that high-level construals of an activity should emphasize desirability concerns, whereas lowlevel construals emphasize feasibility concerns [17].

The current study investigates how to design mobile messages in order to increase the effectiveness mobile in-store advertising. In the context of CLT and message persuasion, the concept of processing fluency, which is defined as "the ease with which people identify and recognize stimulus" (p. 151) [25] has been introduced [26]. Research has shown that when psychological distance and the construal level are congruent (close and low; far and high), cognitive processing is more fluent [27] than when they are incongruent (close and high; far and low). Processing fluency increases in turn the effectiveness of a message [26].

\subsection{Research Hypotheses}

2.2.1. Direct effects. With the advances of indoor positioning systems, customers can receive mobile in-store promotions at different locations during the shopping trip (spatial distance). As proposed by CLT, spatial distance, which is one dimension of psychological distance, is regarded as the distance between the individual and the focal place [28]. Depending on the customer's spatial distance to an event or object, different levels of psychological distance are induced, which in turn influence the construal level [29]. In this study, spatial distance 
refers to the distance between the location of the customer within the supermarket and the location of the product, which is promoted by the mobile advertising. Prior research highlights location as the major variable determining the success of mobile marketing [30]. Studies in the field of HumanComputer-Interaction identified that customers who received ads congruent to their location perceive these ads as more valuable and relevant compared to non-congruent ads [31]. In a similar vein, Luo et al. [15] found that consumers were more likely to redeem mobile coupons for cinema tickets when they were close to the cinema. Thus, we hypothesize:

H1: Customers are more likely to choose the advertised product when they receive a mobile instore promotion close to it (shelf) compared to more distant from it (entry, checkout).

Furthermore, retailers are able to provide their customers with personalized promotions [4]. Personalization in retailing is often based on loyalty program data and data mining [32]. On the basis of personal information (e.g. age, gender, preferred products) that is automatically collected by a system, ad content is generated that fits to consumer profiles [33]. Previous research has proven the significant role of personalization for mobile commerce in general [34] and for the effectiveness of mobile advertising in particular [35]. Information System research identified personalization as the key factor influencing consumers' attitude toward mobile advertising [10]. Findings by Aguirre et al. [36] suggested that personalization can significantly increase click-through rates, whereas another study found personalized information increases customer satisfaction and purchase intention which in turn, serves as a driver to the retailer's online sales performance [11]. In the context of offline retailing, Bues et al. [16] showed that personalization leads to a higher purchase intention. Hence, we hypothesize:

H2: Customers are more likely to choose the advertised product when they receive a personalized promotion.

Previous research confirmed the importance of message ad content for the effectiveness of mobile advertising [37]. For example, Roggeveen et al. [38] investigated price and non-price content on in-store digital displays on retail sales. They found message content with price promotions have a stronger impact on the purchases compared to non-price promotions [38]. Price promotions (including priced discounts and coupons) are widely used in retailing [39] aiming to enhance store traffic and to influence consumers' purchase behavior [12]. For example, research confirmed price discounts to positively influence consumers' coupon redemption behavior $[40,41]$. In contrast, retailers can also use non-price promotions, which typically highlights an item without any mention of the price [38]. In this context, previous research highlighted the importance of recommendations in the form of popularity information [17]. In context of retailing, Kowatch and Maass [42] found that mobile recommendation agents were perceived as useful for product information acquisition in stores, increasing consumers' purchase intention. Thus, we hypothesize:

H3: Customers are more likely to choose the advertised product when they receive a price promotion compared to a product recommendation without a price promotion.

2.2.2. Interaction effects. Drawing on the psychological distance of an object, CLT states that messages, which are congruent with spatially related mental representations, will be more persuasive than incongruent messages [26]. In particular, messages showing high-level, goal-oriented, abstract themes will be more persuasive when psychologically distant, whereas messages that include concrete themes will be more persuasive when an object is psychologically proximal [18]. According to this aspect of CLT, Thomas et al. [43] found that when purchases were moved to the near future, price promotions (feasibility considerations) increased the customer's purchase intention. Conversely, when purchases were moved to distant future, information about additional products (desirability considerations) lead to higher purchase intentions.

Transferring this idea to spatial distance, we assume when located close to the advertised product (in front of the shelf of interest), concrete information will lead to a higher likelihood that customers choose the advertised product. In turn, when located farther away of the advertised product (entrance), we assume that abstract information leads to a higher likelihood that customers choose the advertised product. In this way, the mobile in-store promotion is congruent to the location, hence results in cognitive "processing fluency" which in turn is expected to increase the effectiveness of the message [26].

Given this, in the current study, the following conditions are considered to be congruent: 1) personalized price promotions (concrete information) received close to the advertised product, 2) nonpersonalized price promotions (concrete information) received close to the advertised product and 3) personalized recommendations (abstract information) farther away from the advertised product. 
According to CLT, we consider price promotions to be a concrete information [43]. Regarding personalization, we assume that personalized information, which tends to match to the customer's self [44] appears more concrete and less abstract to them. Therefore, personalization will be considered to represent concrete information. Lastly, personalized recommendations will be assumed to appear more abstract. Although the recommendation is personalized, general information about products (e.g. brand, names, features) belong to abstract information [43, 45, 46], thus it is considered to be more abstract than concrete for customers. Given this, we hypothesize:

H4a: Personalized price promotions (concrete) will be more persuasive when spatially close to the advertised product, leading to a higher likelihood that customers choose the advertised product than when confronted with non-personalized price promotions (concrete) or personalized recommendations (abstract).

H4b: Personalized recommendations (abstract) will be more persuasive when spatially distant to the advertised product, leading to a higher likelihood that customers choose the advertised product than when confronted with non-personalized price promotions (concrete) or personalized price promotions (concrete).

\section{Method and Results}

We conducted two pilot studies to test different stimuli and scenarios in an online choice setting. Finally, we used a between-subjects experimental design with nine different scenarios to assess our hypotheses.

\subsection{Pilot study 1}

The first pilot study tried to identify 1) product categories to be used for the main choice experiment as well as 2) brands that are displayed in each product category.

3.1.1. Participants and Procedure. Forty-five participants (23 female; $M_{\text {age }}=36.09, S D_{\text {age }}=8.39$ ) were recruited by a German panel provider. We introduced the participants with a grocery shopping scenario. Specifically, respondents were asked to imagine that they had invited two friends for breakfast the next day. For this occasion, they were told to go shopping for groceries at their local supermarket. Afterwards, participants were shown a list of product categories commonly used in food retailing $(N=10$ product categories; i.e., fruits, cereals, coffee, etc.). In order to select product categories, which are relevant for the shopping task, we asked them to mark all categories that they would consider to buy for the described shopping scenario $[46,48]$.

In a next step, participants were presented with specific brands for each category they have selected before. Participants were then asked to choose for all selected product categories those brands they usually buy when they go food shopping. Furthermore, we asked participants to evaluate the functionality of the consumption occasion (hedonic to utilitarian), their involvement into the product categories, the functionality of the category (hedonic to utilitarian) and their purchase habits (planned to unplanned). We measured involvement into the category with three items based on Zaichkowsky [48] using 7-point semantic differential scales. The hedonic or utilitarian nature of consumption occasion and the product category was measured with two 7-point semantic differential scales based on Wakefield and Inman [49] (1= "functional", $7=$ "enjoyment"). A one-item measure was used to measure purchase habit $(1=$ "planned", $7=$ "unplanned").

3.1.2. Results. Participants choose around seven categories on average within the given setup $(M=$ $7.07, S D=2.47)$. The functionality of the consumption occasion was perceived as neither highly hedonic nor highly utilitarian $(M=3.56, S D=1.89)$.

With regard to the stimulus material, one of the important issues for the main study and the target brand (considered as the brand which is advertised by the mobile ad) was to choose a product category as well as brand, which is of relevance for the sample used in this study [50]. Furthermore, the stimulus material also should not be purely hedonic or of utilitarian nature to avoid possible congruencies between the promotion and the product category that may enhance one ad content over another [51, 52].

Thus, we decided to choose the following product categories for the main study: cream cheese (involvement: alpha $=.90, A V E=.83, M=3.32, S D$ $=1.42$; functionality: alpha $=.75, A V E=.80, \mathrm{M}=$ 3.62, $S D=1.61$; habit: $M=3.47, S D=1.47$ ), marmalade (involvement: alpha $=.93, A V E=.87, M$ $=3.71, S D=1.49$; functionality: alpha $=.70, A V E=$ .78, $M=4.50, S D=1,76$; habit: $M=3.87, S D=$ 2.16), and orange juice (involvement: alpha $=.91$, $A V E=.84, M=4.07, S D=1.46$; functionality: alpha $=.86, A V E=.88, M=4.80, S D=1.75$; habit: $M=3.97, S D=2.02$ ).

With regard to the brands, we decided not to consider the most frequently selected brands to avoid 
ceiling and floor effects [47]. Therefore, we chose brands, which were the third or fourth most selected choice brand.

\subsection{Pilot study 2}

The second pilot study had the purpose to test the shopping scenario and to select our stimulus material (i.e., mobile ads).

3.2.1. Participants and procedure. Sixty-four participants (31 female; $M_{\text {age }}=39.96, S D_{\text {age }}=16.99$ ) were recruited by a German panel provider. First, two scenarios were tested, where half of the participants tested a scenario with text information only and half of the participants tested a scenario with supporting images showing the entry, different product shelfs and the cashpoint-area of a concrete supermarket. In a similar way to Hong et al. [53], we provided participants with a shopping list with two fixed products (coffee and butter) which they had to buy. All the other purchases were explicitly free to choose [53]. Moreover, participants were told they had the amount of $12 €$ with which to purchase products. Respondents were presented with a series of choice sets. In line with results from pilot study 1 , we used seven product categories. Each participant made decisions in the following product categories (fresh fruits and vegetables, marmalade, coffee, orange juice, cream cheese, butter and partial baked rolls). For each product category, participants were asked to choose one of the displayed brands. If none of the alternatives was of interest, they could choose "none of these" (except for butter and coffee). Photo realistic images with the prices of the products as well as the names of the brands were shown for each product choice.

First, to ensure that the participants completely engaged in the shopping task by experiencing concentration and enjoyment, we used the concept of flow to test our scenarios [54]. Flow of each scenario was measured with two constructs (flow1; flow2) based on Ghani and Deshpande [55]. Flow1 was obtained with six items while flow2 was measured with four items, using 7-point Likert scale for all questions (1= "strongly agree", 7= "strongly disagree"). The credibility of each promotional scenario was tested with a 7-point semantic differential scale $(1=$ "believable"; $7=$ "not believable") by Alnazer [51].

Second, three different mobile coupons with regard to personalization (yes, no) and ad content (price promotion, recommendation without price promotion) were designed with Adobe Photoshop and used for the three selected categories and brands from pilot study one. All participants had to evaluate 9 stimuli in total.

Four measures were obtained for each coupon: attractiveness, personalization perception, intention to buy and credibility. We obtained attractiveness with a one-item scale (1= "strongly agree", 7= "strongly disagree") based on Büttner et al. [39]. Another one-item measure was used to obtain perceived personalization with a 7-point semantic differential scale $(1=$ "very personalized"; $7=$ "not personalized at all"). We measured intention to buy with two items based on Kim et al. [56]. For credibility we used the same scale as in pilot study one.

3.2.2. Results. We selected the first scenario because of the values with regard to flow1 (alpha $=.75, A V E$ $=.65 ; M=2.15, S D=1.21$ ), flow2 (alpha $=.81, A V E$ $=.66 ; M=2.84, S D=1.67)$ and its credibility $(M=$ $2.45, S D=1.60)$. The values of flow indicate that participants were engaged in the shopping task, confirming that the scenario was designed appropriately for the current research work. With regard to the categories and brands, we selected cream cheese and the respective brand as our target brand for the main experiment because of its values with regard to attractiveness $(M=4.07, S D=2.53)$, intention to buy $(M=4.10, S D=2.09$; Cronbach's alpha of each coupon exceeded the value of .97; all $A V E$ s exceeded the value of .97), and credibility ( $M$ $=2.83, S D=1.49$ ). Furthermore, stimuli showed the expected significant differences in personalization perceptions (personalized: $M=3.20, S D=1.70$; nonpersonalized: $M=3.97, S D=1.95 ; F(1,190)=7.78$, $p \leq 0.01)$.

\subsection{Main Experiment}

Based on nine scenarios divided into the factors location (i.e., the location participants receive the mobile ad: entrance, shelf, checkout), personalization (i.e., mobile ad contains personalized promotion vs. non-personalized promotion), and type of offer (i.e., mobile ad shows a price promotion vs. a recommendation without price promotion) a between-subject experimental design was used to test our hypotheses.

3.3.1. Participants and procedure. For the main online choice experiment, we recruited 625 participants (276 female, $M_{\text {age }}=37.21, S D_{\text {age }}=8.58$ ) from a German panel provider. Participants were randomly assigned to one of the 9 treatment scenarios with 67 to 74 participants within each cell. Each participant was exposed to one particular ad content 
at one specific location. We manipulated the location where the participants received the mobile coupon within the supermarket (to be either at the entrance, at the shelf or at the checkout) and the content of the mobile coupon (either personalized price promotion, a non-personalized price promotion or a personalized recommendation without price promotion).

Additionally, if the advertised product was not selected, we asked participants at the checkout within the scenario, how likely they would consider to going back for the advertised product.

First, we introduced the participants with the same grocery-shopping scenario used in pilot study two.

Participants were briefed to assume they had installed the app of the retailer and that they would activate the app to receive mobile coupons during their shopping trip at the supermarket. After this, the choice experiment began.

After the choice task, the participants responded to a post-questionnaire, including questions concerning the scenario (flow, credibility, realistic), product category (involvement), target brand (familiarity, purchase frequency) and mobile advertisement (attractiveness, credibility, evaluation of personalized vs. non-personalized information). All relevant constructs measured on seven-point Likert-scales ( $1=$ "strongly agree", 7= "strongly disagree") or semantic differential scales were assessed. We obtained all constructs with scales used in pilot study one and two. Moreover, we used a oneitem measurement for familiarity (1= "familiar", 7= "not familiar") based on Thompson and Hamilton [57]. Perceived realism of the scenario was tested with a 7-point semantic differential scale (1= "realistic", 7= "not realistic"), while purchase frequency of the brand was measured with a 7-point semantic differential scale $(1=$ "very frequent", $7=$ "never") based on Sethuraman and Cole [58], using for both one-item measurement. Our dependent variable is choice of the target brand. This measure takes on the value of 1 for the chosen brand and 0 otherwise [46].

3.3.2. Results. First, within a preliminary analysis, participants showed 1) a satisfactory evaluation of the overall flow of with the scenario (flow1: alpha $=.91$, $A V E=.76, M=1.78, S D=1.01$; flow2: alpha $=.86$, $A V E=.71, M=3.04, S D=1.37)$. Furthermore, they evaluated the scenario as realistic $(M=2.56, S D=$ $1.51)$ and credible $(M=2.46, S D=1.35)$. For the product category, participants showed 2) a positive involvement similar to the two pilot studies (alpha $=$ .94; $A V E=.88, M=3.65, S D=1.64)$. With regard to 3 ) the target brand, a high value of familiarity $(M=$ $1.81, S D=1.31$ ) and a moderate value of purchase frequency $(M=4.76, S D=1.84)$ led to the conclusion that we reached a satisfactory level of external validity with the product stimulus. Finally, 4) the mobile advertisement showed positive values of credibility $(M=2.68, S D=1.53)$ and advertisement attractiveness $(M=3.04, S D=1.69)$ as well as a distinction between personalized and nonpersonalized information (personalized: $M=3.80, S D$ $=1.95$; non-personalized: $M=4.14, S D=1.93 ; t(623)$ $=2.02, p=.044)$. Therefore, the manipulation of personalization worked as intended.

Second, with regard to the choice process, overall the target brand was selected 123 times in relation to 625 decisions, resulting in a positive share of 19.7 percent. We found significant differences in the selection of the target brand between the scenarios based on differences in location $(\mathrm{L}, 1=$ entry, $2=$ shelf, $3=$ checkout $)$, personalization $(\mathrm{P}, 0=$ no; $1=$ yes), and ad content (Ad, 1 = price promotion, $2=$ recommendation).

\begin{tabular}{|c|c|c|c|c|}
\hline \multicolumn{3}{|c|}{ Scenario } & \multirow{2}{*}{$\mathbf{N}$} & \multirow{2}{*}{$\begin{array}{c}\text { Selected } \\
(\text { count/in \%) }\end{array}$} \\
\hline $\mathbf{L}$ & $\mathbf{P}$ & Ad & & \\
\hline 1 & 1 & 1 & 70 & $20(26.6)$ \\
\hline 1 & 0 & 1 & 67 & $13(19.4)$ \\
\hline 1 & 1 & 2 & 70 & $10(14.3)$ \\
\hline 2 & 1 & 1 & 69 & $36(52.2)$ \\
\hline 2 & 0 & 1 & 69 & $23(33.3)$ \\
\hline 2 & 1 & 2 & 67 & $14(20.9)$ \\
\hline 3 & 1 & 1 & 74 & $2(2.7)$ \\
\hline 3 & 0 & 1 & 70 & $4(5.7)$ \\
\hline 3 & 1 & 2 & 69 & $1(1.4)$ \\
\hline
\end{tabular}

Furthermore, in general if the target brand was not selected within the buying process, the advertisement has almost no effect at the checkout within all scenarios (entry: $M=5.73, S D=1.78$; shelf: $M=$ $5.80, S D=1.60$; checkout: $M=5.20, S D=2.13$ ).

Third, in order to test the hypotheses on the main effects $(\mathrm{H} 1-\mathrm{H} 3)$ a nominal logistic regression was conducted with selection of the target product as dependent variable (not selected and selected with not selected as reference category). The main interest of the current analysis was to test the effects of location (entry, shelf, checkout (checkout represents our control group), personalization (personalized, non-personalized) and ad content (price promotion, recommendation) $\left(X^{2}(4, N=123)=97.73, p<.001\right.$; Cox-Snell $=.15 ;$ Nagelkerke $=.23$, McFadden $=.16)$. Results indicate a strong significant effect of location $(p<.001)$ and ad content $(p<.001)$ and a moderate effect of personalization $(p=.035)$ (see table 2 for 
complete results).

\begin{tabular}{|c|c|c|c|}
\hline Variable & B & OR $(95 \% \mathrm{CI})$ & SE \\
\hline \multicolumn{4}{|l|}{ Location } \\
\hline Entry & 2.09 & $\begin{array}{l}8.09 * * * \\
(3.53,18.56)\end{array}$ & .42 \\
\hline Shelf & 2.86 & $\begin{array}{l}17.52 * * * \\
(7.77,39.49)\end{array}$ & .42 \\
\hline Check-Out & & 1 & \\
\hline \multicolumn{4}{|l|}{ Personalization } \\
\hline $\begin{array}{l}\text { Non- } \\
\text { Personalized }\end{array}$ & -.53 & $\begin{array}{l}0.59 * \\
(0.36,0.96)\end{array}$ & .25 \\
\hline Personalized & & 1 & \\
\hline \multicolumn{4}{|l|}{ Ad content } \\
\hline Recommendation & -1.14 & $\begin{array}{l}0.32 * * * \\
(0.19,0.55)\end{array}$ & .28 \\
\hline Price promotion & & 1 & \\
\hline
\end{tabular}

Table 2. Direct effects

Fourth, in order to test the hypotheses on the interaction effects $(\mathrm{H} 4 \mathrm{a}, \mathrm{H} 4 \mathrm{~b})$, we added the interaction terms to our nominal logistic regression. The main interest of the current analysis was to test the effects of the three-way interaction between location (entrance, shelf, checkout (as control condition), personalization (personalized, nonpersonalized) and ad content (price promotion, recommendation) $\left(X^{2}(8, N=123)=101.26, p<.001\right.$; Cox-Snell $=.15$; Nagelkerke $=.24$, McFadden $=.16$ ). The results, 1) confirm the assumption of a stronger effect of personalized price promotions when participants are close to the advertised product (shelf) (H4a) and 2) do not confirm the assumption of a stronger effect of personalized recommendations when participants are distant to the advertised product (e.g. entry) (H4b), (see table 3 for complete results).

\begin{tabular}{|l|l|l|c|l|c|}
\hline \multicolumn{3}{|c|}{ Variable } & B & OR (95\% CI) & SE \\
\hline 1 & 1 & 1 & 2.67 & $\begin{array}{l}14.40^{* * *} \\
(3.22,64.39)\end{array}$ & .76 \\
\hline 1 & 0 & 1 & 2.16 & $\begin{array}{l}8.67^{* *} \\
(1.88,40.02)\end{array}$ & .78 \\
\hline 1 & 1 & 2 & 1.79 & $\begin{array}{l}6.00^{*} \\
(1.27,28.45)\end{array}$ & .79 \\
\hline 2 & 1 & 1 & 3.67 & $\begin{array}{l}39.27^{* * *} \\
(8.92,172.92)\end{array}$ & .76 \\
\hline 2 & 0 & 1 & 2.89 & $\begin{array}{l}18.00^{* * *} \\
(4.05,79.99)\end{array}$ & .76 \\
\hline 2 & 1 & 2 & 2.25 & $\begin{array}{l}9.51^{* *} \\
(2.07,43.63)\end{array}$ & .77 \\
\hline
\end{tabular}

\begin{tabular}{|l|l|l|l|l|c|}
\hline 3 & 0 & 1 & .78 & $\begin{array}{l}2.18 \\
(0.39,12.31)\end{array}$ & .88 \\
\hline 3 & 1 & 2 & -.64 & $\begin{array}{l}0.53 \\
(0.05,5.97)\end{array}$ & 1.24 \\
\hline 3 & 1 & 1 & & 1 & \\
\hline \multicolumn{3}{|l|}{$\begin{array}{l}\text { Note. Reference group: not selected }(\mathrm{n}=502) . \mathrm{B}=\text { Coefficient; } \\
\text { OR }=\text { Odds ratio. SE }=\text { Standard error. 95\% CI = Confidence } \\
\text { interval. } * p<.05 ; * * p<.01 ; * * * p<.001\end{array}$} \\
\hline
\end{tabular}

Table 3. Interaction effects

Fifth, to rule out effects of habit for the target brand and to check for the effectiveness of the advertisements, participants, who selected the target brand 1) evaluated the advertisement as important for their decision-process (86.1\%) and 2) stated a moderate probability of selecting the product without an advertisement $(M=4.41, S D=1.88)$.

\section{Discussion and Implications}

The results of this study offer interesting insights into the effects of location, personalization and ad content on customers' choice behavior in stores.

In line with previous research (e.g. $[59,9,15])$, the results clearly show that location has the strongest impact on the effectiveness of mobile instore advertising. Customers receiving a mobile promotion close to the advertised product, were more likely to choose the advertised product than customers exposed to promotions farther away. The findings suggest that for marketing campaigns, retailers should provide their customers with promotions, which are congruent to their location within the supermarket.

Moreover, this research demonstrates that the effectiveness of mobile in-store advertising depends on the ad content. Consistent to previous research [60], the findings show that price promotions clearly outperform non-price promotions. In particular, price promotions strongly increase the likelihood that customers choose the advertised product.

Personalization impacts customers' in-store choice behavior. Although prior research highlighted the importance of personalization for mobile advertising [36], surprisingly, our results confirmed the effect only on a moderate level. Nevertheless, personalized mobile in-store promotions are more effective compared to non-personalized ones. However, tailoring mobile ads to the customer's purchase history is expensive, and based on the moderate effect shown in this research, retail practitioners have to think carefully about this option in their specific context.

One of the main findings, representing an important contribution of our research, is that 
personalization in combination with price promotions were most effective regarding the choice of the target product when spatially close to the product. In line with CLT [43], findings farther demonstrate that non-personalized price promotions are also effective when received close to the product, resulting in the second highest likelihood of target product selection. Given this and in line with CLT, results show that particularly at the shelf, retailers should only deliver concrete content (price promotion) in order to increase the choice of the target product.

In the context of our study, personalization appears as an amplifying effect, strengthening the impact of content at the shelf. Another interesting finding to emerge from the data is that the effect occurred only when personalization is combined with price promotions (concrete information). When combined with recommendations (abstract information) the amplifying effect diminishes. Consequently, retailers, have to focus on delivering ad content at the shelf. If they have access to the customers' personal information, e.g. due to loyalty programs, personalized price promotions represents the most effective combination with the highest impact on the actual choice. However, results show that non-personalized price promotions are also effective in our context. Thus, retailers with no access to customer data should focus on the ad content, using price promotions at the shelf of the advertised product. Our findings identify personalization as a sufficient but not necessary precondition for the success of mobile in-store advertising.

Contrary to CLT [43], our findings demonstrate that personalization in combination with price promotions were also most effective regarding the choice of the target product when spatially distant (entry) to the product. It was assumed that at the entry (farther away from the advertised product) customers are receptive to abstract information (personalized recommendations). CLT suggests that message content needs to include abstract themes when spatially distant to the product. One explanation could be that customers do not perceive the spatial distance to the products within the supermarket to be that high and might form already at the entry low-level construals. Hence, customers would be more responsive to concrete information such as price promotions.

Lastly, our findings reveal that mobile in-store ads received spatially close to the checkout have no impact on the customers' choice behavior. In particular, coupons sent at this specific location do not induce customers to buy the advertised product at the current shopping session. Coupons at this location might be more relevant for the next purchase as it is already used by retailers.

\section{Conclusion}

The present study contributes to existing CLT research by showing that CLT can be applied to explain the effectiveness of mobile in-store advertising. In line with CLT, results show that at the shelf, highly concrete content (personalized price promotion) has the strongest impact on the customer's choice of the target product, representing the most effective combination. The present research focus on a specific product category (groceries) which is a major limitation. Future research could replicate our findings to other retail product categories (e.g. hardware or furniture).

\section{References}

[1] D. Grewal, C.-P. Ahlbom, L. Beitelspacher, S. M. Noble, and J. Nordfält, "In-Store Mobile Phone Use and Customer Shopping Behavior: Evidence from the Field", $J$. Market (82:4), 2018, pp. 102-126.

[2] J.J. Inman and H. Nikolova, "Shopper-Facing Retail Technology: A Retailer Adoption Decision Framework Incorporating Shopper Attitudes and Privacy Concerns", $J$. Retailing (93:1), 2017, pp. 7-28.

[3] M.M. Tsang, S.-C. Ho, and T.-P. Liang, "Consumer Attitudes Toward Mobile Advertising: An Empirical Study”, IJEC (8:3), 2004, pp. 65-78.

[4] X. Wang, D. Wu, and H.-H. Teo, "Right Message at Right Place: Investigating the Effectiveness of Locationbased Mobile Advertising on Consumers' Redemption Responses", $35^{\text {th }}$ ICIS, 2014, pp. 1-8.

[5] S.Y.X. Komiak and I. Benbasat, "The Effects of Personalization and Familiarity on Trust and Adoption of Recommendation Agents", MIS Quarterly (30:4), 2006, pp. 941-960.

[6] A. Scharl, A. Dickinger, and J. Murphy, "Diffusion and Success Factors of Mobile Marketing", Electron Commer $R$ $A$ (4:2), 2005, pp. 159-173.

[7] M. Linzmajer, S. Schopfer, T. Keller, L. Nagengast, E. Fleisch, and T. Rudolph, "The Effects of Personalized Recommendations with Popularity Information on Sales A Field. Study in Grocery Retailing", $23^{\text {th }}$ ECIS, 2015, pp. $1-11$.

[8] D. Molitor, P. Reichhart, M. Spann, and A. Ghose, "Measuring the Effectiveness of Location-Based Advertising: A Randomized Field Experiment", 2017, 
available at SSRN: https://ssrn.com/abstract=2645281.

[9] S. Spiekermann, M. Rothensee, and M. Klafft, "Street marketing: How proximity and context drive coupon redemption", J. Consum. Market (28:4), 2011, pp. 280-289.

[10] D.J. Xu, "The influence of personalization in affecting consumer attitudes toward mobile advertising in China", $J$. Computer Information Systems (47:2), 2007, pp. 9-19.

[11] N. Thongpapanl and A.R. Ashraf, "Enhancing Online Performance through Website Content and Personalization”, J. Computer Information Systems (52:1), 2011, pp. 3-13.

[12] D. Grewal, R. Krishnan, J. Baker, and N. Borin, "The effect of store name, brand name and price discounts on consumers' evaluations and purchase intentions", $J$. Retailing (74:3), 1998, pp. 331-352.

[13] K.L. Ailawadi, J.P. Beauchamp, N. Donthu, D.K. Gauri, and V. Shankar, "Communication and Promotion Decisions in Retailing: A Review and Directions for Future Research", J. Retailing (85:1), 2009, pp. 42-55.

[14] K. Gedenk, S.A. Neslin, and K.L. Ailawadi, "Sales promotion", in Krafft, M. and Mantrala, M.K. (Eds.), Retailing in the 21st Century: Current and Future Trends, Springer, Berlin, 2010.

[15] X. Luo, M. Andrews, Z. Fang, and C.W. Phang, "Mobile Targeting", Manage Sci (60:7), 2014, pp. 17381756.

[16] M. Bues, M. Steiner, M. Stafflage, and M. Krafft, "How Mobile In-Store Advertising Influences Purchase Intention: Value Drivers and Mediating Effects from a Consumer Perspective", Psychol Market (34:2), 2017, pp. 157-174.

[17] Y. Trope and N. Liberman, "Construal-Level Theory of Psychological Distance", Psychol Rev (117:2), 2010, pp. 440-463.

[18] S.J. Katz and S. Byrne, "Construal Level Theory of Mobile Persuasion", Media Psychol (16:3), 2013, pp. 245271.

[19] Y. Trope, N. Liberman, and C. Wakslak, "Construal Levels and Psychological Distance: Effects on Representation, Prediction, Evaluation, and Behavior", $J$. Consum Psychol (17:2), 2007, pp. 83-95.

[20] Y. Trope and N. Liberman, "Temporal Construal", Psychol Rev (110:3), 2003, pp. 403-421.

[21] L. Shmueli, I. Benbasat, and R.T. Confetelli, "A Construal-Level Approach to Persuasion by Personalization", $37^{\text {th }}$ ICIS, 2016, pp. 1-19.
[22] R. Dhar and E.Y. Kim, "Seeing the Forest or the Trees: Implications of Construal Level Theory for Consumer Choice", J. Consum Psychol (17:2), 2007, pp. 96-100.

[23] K. Fujita, Y. Trope, N. Liberman, and M. Levin-Sagi, "Construal Levels and Self-Control", J. Pers Soc Psychol, (90:3), 2006, pp. 351-367.

[24] N. Liberman and Y. Trope, "The Role of Feasibility and Desirability Considerations in Near and Distant Future Decisions: A Test of Temporal Construal Theory", J. Pers Soc Psychol (75:1), 1998, pp. 5-18.

[25] A.Y. Lee and A.A. Labroo, "The Effect of Conceptual and Perceptual Fluency on Brand Evaluation", J. Market Res (41:2), 2004, pp. 151-165.

[26] H. Kim, A.R. Rao, and A.Y. Lee, "It's Time to Vote: The Effect of Matching Message Orientation and Temporal Frame on Political Persuasion", J. Consum Res (35:6), 2009 , pp. $877-889$.

[27] T.M. Benning, E. Breugelmans, and B.G.C. Dellaert, "Consumers' evaluation of allocation policies for scarce health care services: Vested interest activation trumps spatial and temporal distance", Market Lett (23:3), 2012, pp. 531-543.

[28] W. Mischel, E.B. Ebbesen, and A. Raskoff Zeiss, "Cognitive and attentional mechanisms in delay of gratification", J. Pers Soc Psychol (21:2), 1972, pp. 204218.

[29] B.K. Kim, G. Zauberman, and J.R. Bettman, "Space, time, and intertemporal preference", J. Consum Res (39:4), 2012, pp. 867-880.

[30] M. Leppäniemi and H. Karjaluoto, "Factors influencing consumers' willingness to accept mobile advertising: A conceptual model", Int J. Mob Commun (3:3), 2005, pp. 197-213

[31] A.E. Hühn, V.-J. Khan, P. Ketelaar, J. van 't Riet, R. Konig, E. Rozendaal, N. Batalas, and P. Markopoulos, "Does location congruence matter? A field study on the effects of location-based advertising on perceived ad intrusiveness, relevance \& value", Comput Hum Behav (73), 2017, pp. 659-668.

[32] D. Grewal, K.L. Ailawadi, D. Gauri, K. Hall, P. Kopalle, and J.R. Robertson, "Innovations in Retail Pricing and Promotions", J. Retailing (87:1), 2011, pp. S43-S52.

[33] B. Zhang, N. Wang and H. Jin, "Privacy Concerns in Online Recommender Systems: Influences of Control and User Data Input", Symposium on Usable Privacy and Security, 2008, pp. 159-173.

[34] L. Zhang, J. Zhu, and Q. Lui, “A meta-analysis of 
mobile commerce adoption and the moderating effect of culture", Comput Hum Behav (28:5), 2012, pp. 1902-1911.

[35] D.J. Xu, S.S. Liao, and Q. Li, "Combining empirical experimentation and modeling techniques: A design research approach for personalized mobile advertising applications", Decis Support Syst (44:3), 2008, pp. 710724.

[36] E. Aguirre, D. Mahr, D. Grewal, K. de Ruyter, and M. Wetzels, "Unraveling the personalization paradox: The effect of information collection and trust-building strategies on online advertisement effectiveness", J. Retailing (9:1), 2015, pp. 34-49.

[37] K.-Y. Goh, J. Chu, and J. Wu, "Mobile Advertising: An Empirical Study of Temporal and Spatial Differences in Search Behavior and Advertising Response", J. Interact Mark (30), 2015, pp. 34-45.

[38] A.L. Roggeveen, J. Nordfält, and D. Grewal, "Do Digital Displays Enhance Sales? Role of Retail Format and Message Content”, J. Retailing (92:1), 2016, pp. 122-131.

[39] O.B. Büttner, A. Florack, and A.S. Göritz, "How shopping orientation influences the effectiveness of monetary and nonmonetary promotions", Eur J. Market (49:1/2), 2015, pp. 170-189.

[40] G. Chakraborty and C. Cole, "Coupon characteristics and brand choice", Psychol Market (8:3), 1991, pp. 145159.

[41] R. Venkatesan and P.W. Farris, "Measuring and Managing Returns from Retailer-Customized Coupon Campaigns", J. Market (76:1), 2012, pp. 76-94.

[42] T. Kowatsch and W. Maass, "In-store consumer behavior: How mobile recommendation agents influence usage intentions, product purchases, and store preferences", Comput Hum Behav (26:4), 2010, pp. 697-704.

[43] M. Thomas, S. Chandran, and Y. Trope, "The effects of temporal distance on purchase construal", Cornell University, unpublished manuscript, 2006.

[44] S. Kalyanaraman and S.S. Sundar, "The Psychological Appeal of Personalized Content in Web Portals: Does Customization Affect Attitudes and Behavior?", J. Commun (56:1), 2006, pp. 110-132.

[45] D. Sheehan and K. Van Ittersum, "So Close, Yet So Far Away: The Influence of Temporal Distance on Mobile Promotion Redemption during a Shopping Experience", Adv Consum Res (41), 2013, pp. 222-224.

[46] J.J. Inman, A.C. Peter, and P. Raghubir, "Framing the Deal: The Role of Restrictions in Accentuating Deal Value", J. Consum Res (24:1), 1997, pp. 68-79.
[47] A.Y. Lee, "Effects of Implicit Memory on MemoryBased versus Stimulus-Based Brand Choice", J. Market $\operatorname{Res}$ (39:4), 2002, pp. 440-454.

[48] J.L. Zaichkowsky, "Measuring the Involvement Construct", J. Consum Res (12:3), 1985, pp. 341-352.

[49] K.L. Wakefield and J.J. Inman, "Situational price sensitivity: the role of consumption occasion, social context and income", J. Retailing, (79:4), 2003, pp. 199-212.

[50] M. Palazon and E. Delgado-Ballester, "Effectiveness of price discounts and premium promotions", Psychol Market (26:12), 2009, pp. 1108-1129.

[51] M. Alnazer, "The moderating role of promotional benefit level and brand awareness on the effectiveness of price discount and premium", Adv Manage (6:12), pp. 4047.

[52] P. Chandon, B. Wansink, and G. Laurent, "A Benefit Congruency Framework of Sales Promotion Effectiveness", J. Market (64:4), 2000, pp. 65-81.

[53] S. Hong, K. Misra, and N.J. Vilcassim, "The Perils of Category Management: The Effect of Product Assortment on Multicategory Purchase Incidence", J. Market (80:5), 2016, pp. 34-52.

[54] J.A. Ghani, R. Supnick, and P. Rooney, "The experience of flow in computer-mediated and in face-toface groups", Proceedings of the ICIS, 1991, pp. 229-237.

[55] J.A. Ghani and S.P. Deshpande, "Task Characteristics and the Experience of Optimal Flow in Human-Computer Interaction”, J. Psychol (128:4), 1994, pp. 381-383.

[56] H.W. Kim, H.C. Chan, and S. Gupta, "Value-based adoption of mobile internet: an empirical investigation", Decis Support Syst (43:1), 2007, pp. 111-126.

[57] D.V. Thompson and R.W. Hamilton, "The Effects of Information Processing Mode on Consumers' Responses to Comparative Advertising", J. Consum Res (32:4), 2006, pp. 530-540.

[58] R. Sethuraman and C. Cole, "Factors influencing the price premiums that consumers pay for national brands over store brands", JPBM (8:4), 1999, pp. 340-351.

[59] S. Banerjee and R.R. Dholakia, "Mobile Advertising: Does Location Based Advertising Work?", Int J. Mob Market (3:2), 2008, pp. 68-75.

[60] D. Hardesty and W. Bearden, "Consumer Evaluations of Different Promotion Types and Price Presentations: The Moderating Role of Promotional Benefit Level", $J$. Retailing (79:1), 2003, pp. 17-25. 